\title{
Retraction: Application of near-infrared spectroscopy in clinical neurology
}

\author{
Yoo Hwan Kim', Byung-Jo Kim², and Jong Seok Bae ${ }^{3}$ \\ 'Department of Neurology, Hangang Sacred Heart Hospital, Hallym University College of Medicine, Seoul, Korea \\ ${ }^{2}$ Department of Neurology, Korea University Anam Hospital, Korea University College of Medicine, Seoul, Korea \\ ${ }^{3}$ Department of Neurology, Kangdong Sacred Heart Hospital, Hallym University College of Medicine, Seoul, Korea
}

I deeply regret to inform you and request for retraction of the review article entitled "Application of near-infrared spectroscopy in clinical neurology" published in ACN 1) This review article was published in advance to Journal of the Korean Neurological Association. 2) as a review article, which should have been addressed for the publication in ACN as duplication. As the corresponding author, I will take full responsibility and respectfully request for the retraction of the paper from $\mathrm{ACN}$.

1) Kim YH, Paik S, Va ZP, Seok HY, Jeon NJ, Kim BM, et al. Aortic dissection and rupture in a child. Ann Clin Neurophysiol 2018;20:3-11.

2) Kim YH, Kim BJ, Bae JS. Application of Near-Infrared Spectroscopy in Neurological Disorders: Especially in Orthostatic Intolerance. J Korean Neurol Assoc 2017;35:8-15. 